\title{
SPINE20 A global advocacy group promoting evidence-based spine care of value
}

\author{
Sami I. AlEissa ${ }^{1} \cdot$ Koji Tamai $^{2}$ - Faisal Konbaz ${ }^{1}$. Ahmed Alturkistany ${ }^{3}$. Thomas R. Blattert ${ }^{4} \cdot$ Harvinder S. Chhabra $^{5}$. \\ Giuseppe Costanzo ${ }^{6} \cdot$ Edward J. Dohring $^{7} \cdot$ Frank Kandziora $^{8} \cdot$ Ralph Kothe $^{9} \cdot$ Bernardo Misaggi $^{10}$. \\ Eric J. Muehlbauer ${ }^{11}$. Paulo Pereira ${ }^{12}$. Shanmuganathan Rajasekaran ${ }^{13} \cdot$ William J. Sullivan $^{14}$. \\ Eeric Truumees ${ }^{15}$. Yahya Alqahtani ${ }^{16} \cdot$ Hana I. Alsobayel $^{17}$. Joerg Franke ${ }^{18} \cdot$ Marco G. A. Teli $^{19}$. Jeffrey C. Wang ${ }^{20}$. \\ Hazzaa M. Al-Hazzaa ${ }^{21}$ - Majed Nasser Alosaimi ${ }^{22}$. Sigurd Berven ${ }^{23} \cdot$ Marco Brayda-Bruno $^{24}$. Andrew M. Briggs ${ }^{25}$. \\ Jamiu O. Busari ${ }^{26}$. Antonello-Valerio Caserta ${ }^{27} \cdot$ Pierre Côté $^{28} \cdot$ Marco Crostelli $^{29} \cdot$ Michael G. Fehlings $^{30}$. \\ Robert Gunzburg ${ }^{31}$ - Sami Haddadin ${ }^{32}$. Joseph $\mathrm{Ihm}^{33}$. Alan S. Hilibrand ${ }^{34}$. Andrea Luca ${ }^{35}$ - Mazza Osvaldo ${ }^{29}$. \\ Tim Pigott ${ }^{36}$. Dominique A. Rothenfluh ${ }^{37}$. Carlo Ruosi ${ }^{38} \cdot$ Louis-Rachid Salmi ${ }^{39} \cdot$ Ajoy P. Shetty ${ }^{13} \cdot$ Kern Singh $^{40}$. \\ Alexander R. Vaccaro ${ }^{41}$. David A. Wong ${ }^{11} \cdot$ Mehmet Zileli $^{42} \cdot$ Margareta Nordin $^{43}$
}

Received: 19 March 2021 / Revised: 22 April 2021 / Accepted: 29 May 2021 / Published online: 9 June 2021

(c) The Author(s) 2021

\begin{abstract}
Purpose The Global Burden of Diseases (GBD) Studies have estimated that low back pain is one of the costliest ailments worldwide. Subsequent to GBD publications, leadership of the four largest global spine societies agreed to form SPINE20. This article introduces the concept of SPINE20, the recommendations, and the future of this global advocacy group linked to G20 annual summits.

Methods The founders of SPINE20 advocacy group coordinated with G20 Saudi Arabia to conduct the SPINE20 summit in 2020. The summit was intended to promote evidence-based recommendations to use the most reliable information from high-level research. Eight areas of importance to mitigate spine disorders were identified through a voting process of the participating societies. Twelve recommendations were discussed and vetted.

Results The areas of immediate concern were "Aging spine," "Future of spine care," "Spinal cord injuries," "Children and adolescent spine," "Spine-related disability," "Spine Educational Standards," "Patient safety," and "Burden on economy." Twelve recommendations were created and endorsed by $31 / 33$ spine societies and 2 journals globally during a vetted process through the SPINE20.org website and during the virtual inaugural meeting November 10-11, 2020 held from the G20 platform.

Conclusions This is the first time that international spine societies have joined to support actions to mitigate the burden of spine disorders across the globe. SPINE20 seeks to change awareness and treatment of spine pain by supporting local projects that implement value-based practices with healthcare policies that are culturally sensitive based on scientific evidence.
\end{abstract}

Keywords Spine $\cdot$ SPINE20 $\cdot$ Policy $\cdot$ Recommendations $\cdot$ Global $\cdot$ Evidence $\cdot$ G20 · C20

\section{Introduction}

Improvements in global health measures may be attributed to better identification, prevention, and treatment of communicable diseases throughout the world [1]. However, the world's population is aging and the number of people living

Koji Tamai

koji.tamai.707@gmail.com

Extended author information available on the last page of the article with noncommunicable diseases (NCDs), degenerative disorders, and the consequences of injuries is increasing [2, 3]. The current demographic and health shifts are contributing to a rapid increase in both the number of people experiencing disability and loss of function [4].

Musculoskeletal disorders are among the most predominant NCDs, and of these, spine pain is the leading cause of disability globally. The Global Burden of Disease (GDB) study estimates that, due to low back pain alone, more than half a billion individuals experience loss of function and 
disability worldwide [2]. Traditionally, the World Health Organization (WHO) has focused on the mortality of communicable diseases; however, in 2018 the WHO acknowledged the impact of NCDs and called for action through rehabilitation 2030 [5].

The need to focus on rehabilitation to improve an individual's function, life, and well-being is urgent [4]. The disease category with the highest contribution to disability was that of musculoskeletal disorders (1.71 billion people and 149 million Years Lived with Disability-YLD). Among musculoskeletal disorders, low back pain caused the highest burden, with 568 million people and 64 million YLDs globally. Low back pain was the leading health condition contributing to the need for rehabilitation services in 134 of the 204 countries analyzed. The need for health systems strengthening to address the profound and increasing burden of disease associated with spine pain is well acknowledged, yet little global-level guidance is available $[6,7]$.

Faced with these staggering facts, four of the largest NonGovernmental Organizations (NGOs) from the spine care and research community decided in 2019 to form an advocacy group to bring global attention to spine disorders. This is SPINE20.

\section{Purpose of article}

The purpose of this article is to (1) introduce SPINE20 as a global advocacy group for spine ailments, (2) present proposed recommendations for mitigating spine disorders to governments, institutions, public health organizations, healthcare providers, community leaders, and other interested parties, and (3) advocate for a global agenda, based on evidence, that will be culturally accepted and implemented in every corner of the globe supporting the agenda of the WHO, to immediately target the prevention and treatment of spine disorders.

\section{SPINE20, an introduction}

SPINE20 is an advocacy group founded in 2019 by EUROSPINE, the North American Spine Society, the German Spine Society, and the Saudi Spine Society, to improve spine care and prevention on a global level. In 2020, two new partner societies joined SPINE20, the Italian Spine Society and the Association of Spine Surgeons of India. SPINE20 decided to develop evidence-based policy recommendations for the G20 countries and the global community to alleviate the burden of spine disease, disability, and injuries.

The goal of SPINE20 is to serve as a high-level resource to optimize prevention, access to care, educational, and research options for governments interested in mitigating spine injuries and disorders in their countries. SPINE20 is directing their recommendations to the representative (Sherpa) of G20 members and non-members to raise awareness, to recognize the burden of spine ailments, and to establish actions appropriate for their home country. SPINE20 was registered in 2020 under the $\mathrm{C} 20$ official engagement groups of G20 (https://civil-20.org/). The C20 is a platform of Civil Society Organizations around the world bringing forth political dialogue with the G20. SPINE20 seeks to be a highly recognized civil group voicing the concerns and needs of the spine care community and serving as a resource to address its resolution.

SPINE20 is a unique advocacy group as it focuses on spine ailments globally. It is opening doors for international advocacy and collaboration to prevent spine disability and promote access to evidence-based interventions that are culturally adapted to the needs of a given country. Cultural adaptation in this context refers to the systematic modification of an evidence-based treatment or intervention protocol to consider language, culture, and context in such a way that is compatible with the clients' cultural patterns, meaning, and values.

The inaugural meeting of SPINE20 took place in Riyadh, Saudi Arabia on November 10 and 11, 2020. In 2021, SPINE20 will be held in Italy, in 2022 in Indonesia, and in 2023 in India, each time just prior to the G20 meetings (www.spine20.org).

\section{SPINE20 recommendations}

The following 12 recommendations were deemed to be the most urgent to influence health policy and decision-makers (Fig. 1). The recommendations can be described under three themes: public health, spine care including access, and education including research and innovation.

\section{SPINE20 recommendations for public health}

\section{Recommendation: Develop policies and support systems to mitigate the increasing burden of spinal disability on healthcare, the economy, and social security systems}

Efficiency in the delivery of public services has a direct impact on poverty. There is evidence that countries with independent, meritocratic bureaucracies do a better job of vaccinating children, protecting the most vulnerable members of society, reducing child mortality, and making other healthcare improvements. Studies have shown that public support for a policy can be increased by communicating evidence of its effectiveness [8]. Although the increment of success may be moderate, these policies offer a significant impact on cost and human well-being. Health policy 


\section{SPINE20 inaugural meeting, Riyadh, Saudi Arabia}

\section{RECOMMENDATIONS}

\section{Develop policies and support systems to mitigate the increasing burden of spinal disability on health care, the economy and social security systems.}

Promote balanced nutrition in the young population, to ensure full access to vitamins and nutrients throughout childhood.

Create global awareness for the prevention of Spinal Cord Injury (SCI).

Support projects that improve access to quality spine care for the pediatric population, particularly in areas with limited resources.

Recognize that low back pain is the leading cause of years lived with disability and loss of function in the world. Create low cost models to ensure the right care is delivered at the right time.

Recognize the need to address Patient safety which requires appropriate training and teamwork in spine care.

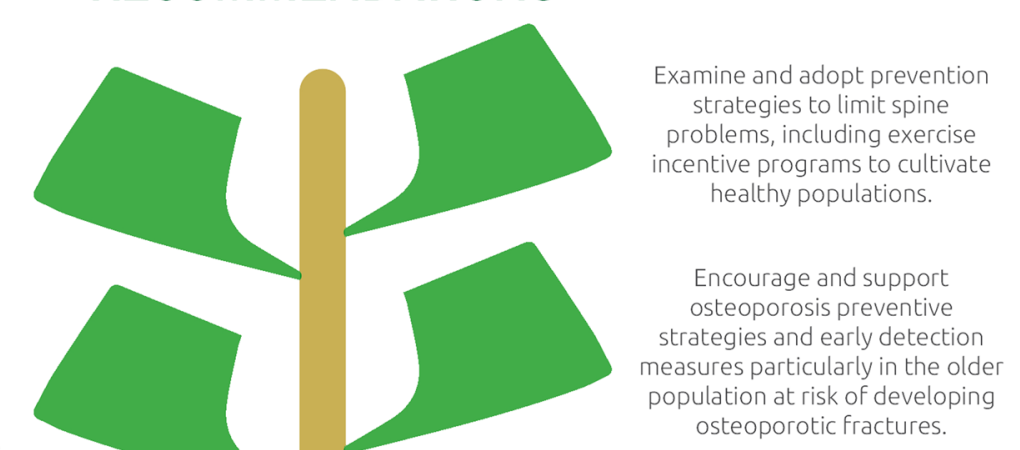

osteoporotic fractures.

Implement the principles of Value-based Health Care in spine practice to optimize spine care in the global community.

Promote global access to comprehensive health care for individuals with spinal cord injury to facilitate community inclusion, return to the workforce and improve quality of life.

Define global standards for continuing education and training curricula for spine care practitioners that promote interprofessional collaboration and patient-centered care.

Create national / global big data collections in the form of registries or other modalities so future care is based on reliable and valid research and outcome data.

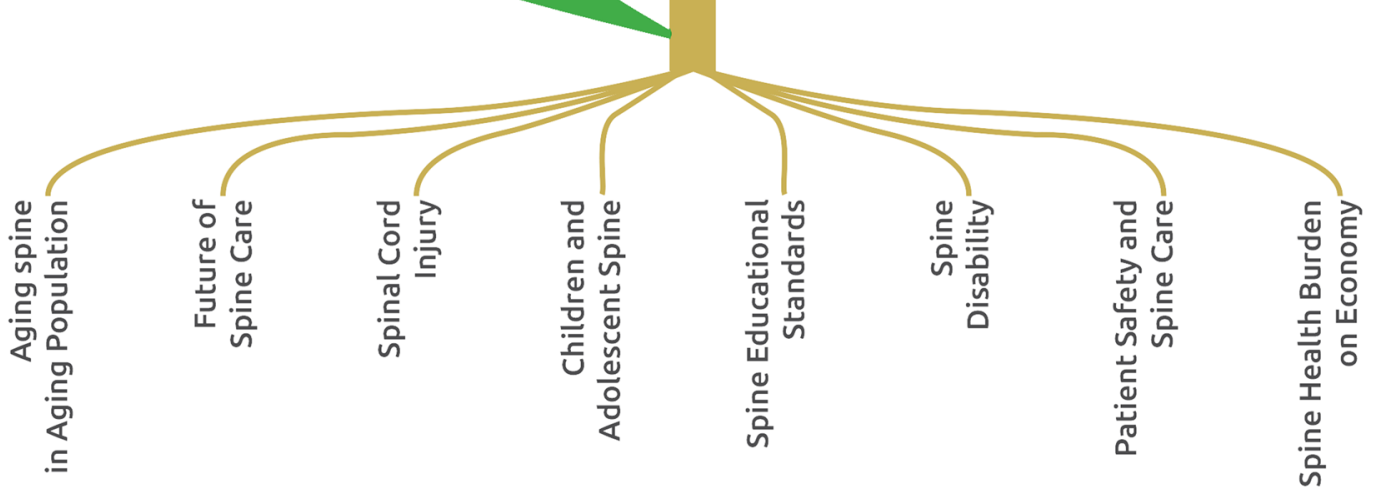

Fig. 1 SPINE20 recommendations to the G20 group 
responses for musculoskeletal conditions such as spine ailments are relatively lacking internationally; however, policy responses remain critical to arresting the disability trajectory of spinal pain [9].

\section{Recommendation: Examine and adopt prevention strategies to limit spine problems, including exercise incentive programs to cultivate healthy populations}

Lower back pain affects 80 to $90 \%$ of the adult population in both industrialized and emerging countries. Evidence suggests that $30 \%$ of affected individuals experience disability and loss of function [4]. Chronic lower back pain leads to loss of function, ability to work, poverty, and the ability to provide for oneself, the family, and the community and is often the primary cause for loss of quality of life [10]. Nations need to recognize that lower back pain is one of the world's leading causes of YLD and loss of function [11]. Investing in public health-including occupational programs to prevent disability by promoting education and physical activity - must be a priority, coupled with systemlevel support, funding models and policy. According to the WHO, one in four adults is not physically active [12]. Perhaps even more alarming, eight out of ten adolescents are not physically active. Physical inactivity costs healthcare systems US $\$ 54$ billion worldwide, with productivity losses of US\$ 14 billion, and 13.4 million disability-adjusted life years [13].

\section{Recommendation: Promote balanced nutrition in the young population, to ensure full access to vitamins and nutrients throughout childhood}

UN-Habitat estimates that there are at least one billion people living in urban slums, that is, places in cities without adequate access to healthcare, clean water, and sanitation. More than $90 \%$ of these slums are in low- and middleincome countries and the residents are usually living in poverty, with little food security [14]. One consequence of an inadequate diet is growth stunting, which is associated with greater susceptibility to infection, cognitive skills and behavioral problems, and lower adult work performance and earnings.

Prevention is one of the most important strategies for maintaining spine health and avoiding degenerative disorders, deformity, and traumatic pathology [15]. Nations must recognize that balanced nutrition, access to nutrients and the fight against malnutrition, undernutrition as well as obesity are fundamental for the treatment of spinal disorders in childhood, adolescence through old age [16]. A balanced diet is fundamental for healthy spinal growth and to maintain function in adulthood through old age.

\section{Recommendation: Encourage and support osteoporosis preventive strategies and early detection measures, particularly in the older population at risk of developing osteoporotic fractures}

Osteoporotic vertebral fractures are common among the elderly population. In a population-based study, vertebral deformities were up to in $25 \%$ of women in Japan and Canada, and $21.5 \%$ of men aged more than 50 years in Canada. In 2005, the USA reported that the osteoporosis morbidity and mortality cost was approximately US\$ 17 billion. The WHO reported that $80 \%$ of elderly people (aged 60 or older) will be living in low- and middle-income countries in 2050 [17]. Osteoporosisrelated fractures often result in chronic pain and disability and affect daily activity, physical activity, and the quality of life of elderly individuals.

There is a need of global action [18]. Screening programs including fracture risk assessment, weight-bearing exercises, proper nutrition with Vitamin D and calcium supplements, and avoidance of tobacco intake reduces the severity of osteoporosis and prevents debilitating fractures among the elderly. Maintaining physical activity and exercise-with special attention to the ability to ambulate and carry out daily activities while preventing falls - help the elderly to remain active and independent in the community [19].

\section{Recommendation: Create global awareness for the prevention of spinal cord injury}

In Spinal Cord Injuries (SCI), prevention is always better than the cure, particularly as there is currently no treatment available to reverse paralysis caused by injury. SCI prevention involves many stakeholders, policymakers, caregivers and society. Successful prevention will reduce exorbitant medical costs and prevent substantial indirect costs related to loss of productivity and social support. To mount a successful SCI prevention program, clear requirements and strategies must be defined. Accurate data and statistics on the causes of injury and the estimated annual cost of spinal cord injuries are required to plan a successful prevention program. For example, road traffic accidents are the primary cause of spinal cord injuries in the Middle East, while sports-related injuries are the primary cause in the far east region [20,21]. Therefore, each region will require a different prevention strategy for a successful prevention program [21]. Community and government involvement are necessary, and frequent evaluations and reviews of the strategy may be needed to continuously adjust programs. 


\section{SPINE20 recommendations for spine care including access}

\section{Recommendation: Implement the principles of Valued-based Healthcare in spine practice to optimize spine care in the global community}

The broad spectrum of spine disorders, huge range of treatment options, diverse professional backgrounds of care providers and rapidly evolving medical and surgical technologies emphasize the complexity of spine clinical practice.

In value-based healthcare models, medical care does not exist in silos. Instead, primary and specialty care are combined in a model of service delivery that is both patient-centered and integrated [22]. It is a coordinated approach to patient care, often led by a patient's primary care professional who directs the patient's whole clinical care team. The valued-based healthcare model is datadriven based on patient-reported outcomes. Spine care must be improved on a global level to mitigate spine disability and costs. Advocacy, education, and government policies are mandated.

\section{Recommendation: Support projects that improve access to quality spine care for the pediatric population particularly in areas with limited resources}

Back pain in children and adolescents is an increasing global concern, yet it often gets overlooked and underrepresented. In recent years, its global prevalence has trended upward from $2-11 \%$ to $27-51 \%$ [23]. Back pain in children has a substantial impact on the children's quality of life and their family dynamics and often results in subsequent diminished physical activity, school absenteeism, and psychological distress. The rise in the incidence of back pain in children should be considered a public health issue as its subsequent contributions to both global burden of disease and its direct impact will have direct implications to healthcare costs imposing a severe socioeconomic burden to society [24].

The major challenge in approaching spine conditions in the pediatric population comes from the wide spectrum of possible etiologies. Health systems worldwide should work in supporting projects that could assure that children have an efficient access to quality spine care, and in improving their ability to early detect potential serious spine conditions. Health systems should also consider implementing proper prevention programs that could help in minimizing the growing incidence of back pain in the young population via controlling the potential risk factors and promoting a healthy lifestyle [25].

Recommendation: Promote global access to comprehensive healthcare for individuals with spinal cord injury to facilitate community inclusion, return to the work force and improve quality of life

The aim of spinal cord injury (SCI) management is to achieve the highest independence possible. The healthcare starts at the time of the injury with proper pre-hospital management, followed by early treatment involving both medical and/or surgical management. The continuum of care continues, with extensive inpatient SCI rehabilitation. Inpatient rehabilitation is followed by a post-hospital program, home healthcare and, if needed, occupational re-training [26]. This approach involves physicians, physiotherapists, occupational therapists, nurses, psychologists, rehabilitation specialists, social workers, psychologists, dieticians, vocational rehabilitation specialists, and other specialties if needed.

To implement this approach, authorities would have to build a sustainable workforce capacity to address the needs of people with SCIs [27]. Currently, a wide variety of applications of this comprehensive approach exists globally. There is, however, a notable absence of such centers in low- and middle-income counties, where major challenges are faced in terms of funding, available resources, and access to care [28].

\section{Recommendation: Recognize that lower back pain is the leading cause of years lived with disability and loss of function in the world. Create low-cost models to ensure the right care is delivered at the right time}

In 2017, the WHO's "Rehabilitation 2030" initiative highlighted the global unmet need for rehabilitation and called for immediate coordinated actions [5]. It is urgent for governments to invest in evidence-based, accessible, and affordable rehabilitation to ensure that individuals can participate in education and work, be economically productive, and fulfill meaningful life roles. Early care by primary care clinicians will decrease chronicity in people with lower back pain [10]. For those individuals who cannot manage their daily living due to back pain, low-cost rehabilitation solutions are available. These interventions include education, promoting activity, and recognizing that some individuals may need help to resolve the problem. The call for action from SPINE20 is to reduce global disability from lower back pain by facilitating access to spine care and putting in place appropriate first-line care pathways. 


\section{SPINE20 Recommendations education including research and innovation}

\section{Recommendation: Define global standards for continuing education and training curricula for spine care practitioners that promote interprofessional collaboration and patient-centered care}

Recognition from governments of the impact of spinal disability and better education of primary care practitioners and public health workers will help reduce disability [29]. Worldwide, most patients with benign spine conditions consult different healthcare professionals who propose a variety of treatments, a large portion of which are ineffective, and not evidence-based [30]. These treatments need to be de-adopted in an evidenceand value-based healthcare system.

Continuing education is required in nearly all professions, but it is of particular importance in healthcare to ensure that professionals maintain their skills and competencies, while they learn about new and developing areas in the field [31]. Thus, developing continuous education programs and opportunities to promote and facilitate shared learning between spine practitioners are key elements in reaching this goal. SPINE20 aims at defining global educational standards and training curricula for spine practitioners and adapting them to local/ regional resources and needs.

\section{Recommendation: Recognize the need to address patient safety which requires appropriate training and teamwork in spine care}

A lack of focus on patient safety will impact the overall outcomes in spine care, leading to social and economic expenditures that could otherwise be avoided. Emerging literature shows how risk stratification programs, teamwork, and technology can all improve patient safety [32]. These programs should be supported in ways that make them feasible, easy to implement, low cost, and with low regulatory burden.

Achieving patient safety is a continuous process and not a one-time event or short-term activity. Patient safety does not come in one single program and is not performed in isolation. Teamwork, multispecialty care, and technology all have roles in patient safety. SPINE20 is calling for a collaborative effort to identify programs and processes that can improve overall patient safety. These efforts will lead to better adoption of programs dedicated to patient safety, improve patient outcomes, limiting burden on providers and minimize costs associated with spine care for the community.
Recommendation: Create national/global big data collections in the form of registries or other modalities in order for future care to be based on reliable and valid outcome data

Exponential growth in information is transforming what governments can do for the people they represent. Data must be reliable, valid, and continuous. It is not possible to transfer results from one population to another; however, we can learn from each other and try to harmonize the data collected. This is where big data is helpful. An international study of 13 registries in five countries (Australia, Denmark, Sweden, the United Kingdom, and the United States) suggests that by making outcome data transparent to both practitioners and the public, well-managed registries enable medical professionals to engage in continuous learning and to identify and share best clinical practices of value, with substantial savings for the government and individuals [33]. Population-based and/or practice-based standardized data can be utilized by national healthcare systems to make their decisions.

Moving forward with SPINE20 SPINE20 is meant to act as a resource for G20 and other nations to provide governments with the expertise needed to improve spine care around the globe. We propose the following steps for exploring/implementing our global spine recommendations:

- Organize introduction meetings with key stakeholders and decision-makers to raise awareness and explore specific topics of interest.

- Engage an independent body to conduct a high-level gap assessment ('health check') comparing the progress of each G20 nation and beyond on each of the SPINE20 recommendations:

- What is in place already today?

- What additional steps would bring the greatest value/ impact?

- What best practice ideas are worth sharing across countries?

Develop a clear calendar of activities and form task-force groups to work on forming evidence-based policy recommendations. SPINE20 recommendations can be accessed on a practical basis by organizing meetings of key stakeholders, and by establishing work groups to assess local and regional needs and resources, toward offering specific evidence- and value-based recommendations for improving spine health (Fig. 2). 
Fig. 2 What SPINE20 can do?

How can SPINE20 help governments and institutions to alleviate the burden of spine

disease and disability?

SPINE20 can:

* Serve as a resource for governments and larger institutions (national or

international) in spine-related healthcare, policies, and prevention action.

* Advocate for the prevention of spinal disorders and injuries.

\# Stimulate innovation to promote spine health.

* Advance spine research through advocacy for funding to improve the ability to care for patients

\# Facilitate access to spine care and treatment to improve function and decrease disability of spine patients.

\section{SPINE20 develops recommendations based on needs The} statutes of SPINE20 recommend that each annual meeting should contain: (1) topics of interest to the host country, (2) subjects addressing the announced theme of the G20 meeting each year, and (3) permanent domains that address universal spine health, spine care including access, spine research including education and innovation.

The SPINE20 will present 6-8 symposia at each meeting. A list of the 14 most urgent topics to mitigate the global burden of spine disorders was created by the 6 societies engaged in the SPINE20 scientific program committee. The process of vetting these topics was made through voting by the Scientific Program Committee $(n=14)$ on a scale scored from 1 to 5 (5 most important topic). Eight major topics were retained (cut off score 3.8) and approved by the SPINE20 Executive Committee for the inaugural meeting. The 8 topics approved were aging spine in aging population, future of spine care, spinal cord injuries, pediatric and adolescent spine, the burden of spine health on the economy, spine educational standards, spine-related disabilities, and patient safety in spine care (Fig. 1).
Two chairpersons each from a different of the 6 participating societies were appointed to invite world experts to debate evidence recommendations that were reviewed and approved by the SPINE20 scientific and executive committees. These recommendations were shared with all SPINE20 invited 206 participants in 27 countries representing 33 global spine societies in advance of the virtual meeting held on November 10-11, 2020. During the inaugural meeting, discussion periods allowed the participants to object and provide comments. All comments were registered by chat or email; and 137 comments were received from individuals one objection was received, and one recommendation was altered. All comments were carefully reviewed and integrated by the Recommendation and Publication Committee; 27 comments that could not be integrated will be considered at the next SPINE20 meeting 2021. The final recommendations are listed above with their respective rationale. Recommendations acted upon from SPINE20 societies will be tracked and presented at the following year's SPINE20 meeting. 
Table 1 Societies and journals endorsed the SPINE20 recommendations in SPINE20 Inaugural Meeting 2020 Riyadh, Saudi Arabia

\begin{tabular}{|c|c|c|}
\hline Country or region & Society & Role in SPINE20 recommendations \\
\hline \multirow[t]{7}{*}{ Saudi Arabia } & Saudi Spine Society (SSS) & $\begin{array}{l}\text { Founding Society SPINE20, planned, developed, authored, reviewed, } \\
\text { and endorsed recommendations. Organized Inaugural Meeting } \\
2020\end{array}$ \\
\hline & Saudi Physical Therapy Association (SPA) & Developed, authored, reviewed, and endorsed recommendations \\
\hline & Saudi Association of Neurological Surgery & Reviewed and endorsed recommendations \\
\hline & Saudi Interventional Radiology Society & Reviewed and endorsed recommendations \\
\hline & Saudi Orthopedic Association & Reviewed and endorsed recommendations \\
\hline & Saudi Rheumatology Association & Reviewed and endorsed recommendations \\
\hline & Saudi Society of Pain Medicine & Reviewed and endorsed recommendations \\
\hline \multirow[t]{2}{*}{ United States of America } & North American Spine Society (NASS) & $\begin{array}{l}\text { Founding Society SPINE20, planned, developed, authored, reviewed, } \\
\text { and endorsed recommendations }\end{array}$ \\
\hline & Scoliosis Research Society (SRS) & $\begin{array}{l}\text { Observed and participated in SPINE20 Inaugural Meeting 2020, Saudi } \\
\text { Arabia, did not endorse recommendations }\end{array}$ \\
\hline \multirow[t]{7}{*}{ Europe } & EUROSPINE & $\begin{array}{l}\text { Founding Society SPINE20, planned, developed, authored, reviewed, } \\
\text { and endorsed recommendations }\end{array}$ \\
\hline & Romanian Society of Spine Surgeons & Reviewed and endorsed recommendations \\
\hline & $\begin{array}{l}\text { NEURORAQUIS; Spanish Society of Ver- } \\
\text { tebral and Spinal Cord Surgery }\end{array}$ & Reviewed and endorsed recommendations \\
\hline & Spanish Spine Society & Reviewed and endorsed recommendations \\
\hline & Hellenic Spine Society & Reviewed and endorsed recommendations \\
\hline & Italian Spine Society (SICV\&GIS) & $\begin{array}{l}\text { SPINE20 Host 2021, partner society SPINE20, developed, authored, } \\
\text { reviewed, and endorsed recommendations }\end{array}$ \\
\hline & German Spine Society (DWG) & $\begin{array}{l}\text { Founding Society SPINE20, planned, developed, authored, reviewed, } \\
\text { and endorsed recommendations }\end{array}$ \\
\hline \multirow[t]{3}{*}{ Asia } & Association of Spine Surgeons India (ASSI) & $\begin{array}{l}\text { SPINE20 Host 2023, partner society SPINE20, developed, authored, } \\
\text { reviewed, and endorsed recommendations }\end{array}$ \\
\hline & Society of Indian Physiotherapist (SIP) & Reviewed and endorsed recommendations \\
\hline & $\begin{array}{l}\text { Japanese Spine Society for Surgery and } \\
\text { Related Research (JSSR) }\end{array}$ & $\begin{array}{l}\text { Observed and participated in SPINE20 meeting 2020, Saudi Arabia, } \\
\text { did not endorse recommendations }\end{array}$ \\
\hline \multirow[t]{10}{*}{ Other Regions } & Brazilian Spine Society & Reviewed and endorsed recommendations \\
\hline & Mexican Society of Spine Surgery & Reviewed and endorsed recommendations \\
\hline & Societies of Spine Surgeons Pakistan & Reviewed and endorsed recommendations \\
\hline & Egyptian Spine Study Group & Reviewed and endorsed recommendations \\
\hline & Egyptian Spine Society & Reviewed and endorsed recommendations \\
\hline & Egyptian Scoliosis Society & Reviewed and endorsed recommendations \\
\hline & Emirates Society of Neurological Surgery & Reviewed and endorsed recommendations \\
\hline & Jordan Spine \& Pain Management & Reviewed and endorsed recommendations \\
\hline & Kuwait Orthopedic Society & Reviewed and endorsed recommendations \\
\hline & Kuwait Spine Society & Reviewed and endorsed recommendations \\
\hline \multirow[t]{4}{*}{ Global Organizations } & World Spine Care & Reviewed and endorsed recommendations \\
\hline & International Spinal Cord Society & Reviewed and endorsed recommendations \\
\hline & International Musculoskeletal Association & Reviewed and endorsed recommendations \\
\hline & World Federation of Chiropractic & Reviewed and endorsed recommendations \\
\hline \multirow[t]{2}{*}{ Spine Journals } & European Spine Journal & Reviewed and endorsed recommendations \\
\hline & Global Spine Journal & Reviewed and endorsed recommendations \\
\hline
\end{tabular}

The following multidisciplinary and interprofessional spine societies, societies interested in spine disorders and journals focused on spine endorsed or observing the SPINE20 recommendations in SPINE20 Inaugural Meeting November 10-11, 2020 Riyadh, Saudi Arabia 


\section{Conclusions}

SPINE20 is created as an advocacy group for governments, institutions, and other organizations to highlight evidence, valued-based spine care and to help preventing disability. The recommendations put forward in this article were approved by $31 / 33$ spine societies and 2 journals from around the world (Table 1). The recommendations are intended to reduce the burden of disease related to spine disorders by engaging governing stakeholders in the development of evidence-based policies. SPINE20 can serve as a resource of expertise for local and/or global advisement to mitigate disability from spine ailments; it is the hope of the founding group that its advocacy will reduce suffering needlessly from disabling pain, through education about rehabilitation and other treatment modalities that can be instituted across the globe.

Acknowledgements Warm thanks go to Princess Nouf Bint Muhammad, Chair of the official G20 Saudi Arabia 2020's Civil Society Engagement Group and the CEO of the King Khalid Foundation for supporting SPINE20 Inaugural Meeting November 10-11, Riyadh, Saudi Arabia 2020. We express our gratitude to Alexandra Rauch PhD, Sensory Functions, Disability and Rehabilitation Unit; Department for Noncommunicable Diseases; World Health Organization; Geneva, Switzerland, for lecturing at the SPINE20 Inaugural Meeting and for reviewing the article.

Author contributions SA, MN, FK and KT led the drafting of this paper in collaboration with the other authors and were part of the team that coordinated the production of papers. ED, TB, HSC, BM, GC, AA, PP, RK, SR, WS, EM, PC and ET closely revised many sections. Thereafter all authors contributed to all sections of the paper and edited it for key intellectual content. In addition to the aforementioned authors, YA, HA, JF, MO, MT and JC participated in the authors' meeting, drafted different sections of the paper, and took part in discussions during the drafting process. All other authors have read and provided substantive intellectual comments to the draft and have approved the final version of the paper.

\section{Funding None.}

Availability of data and material The datasets generated during and/or analyzed during the current study are available from the corresponding author on reasonable request.

\section{Declarations}

Conflicts of interest The authors declare that they have no conflict of interest.

Consent to participate All authors have read and approved the final version of the paper.

Consent for publication All authors give our consent for the publication of identifiable details to be published in the European Spine Journal.
Open Access This article is licensed under a Creative Commons Attribution 4.0 International License, which permits use, sharing, adaptation, distribution and reproduction in any medium or format, as long as you give appropriate credit to the original author(s) and the source, provide a link to the Creative Commons licence, and indicate if changes were made. The images or other third party material in this article are included in the article's Creative Commons licence, unless indicated otherwise in a credit line to the material. If material is not included in the article's Creative Commons licence and your intended use is not permitted by statutory regulation or exceeds the permitted use, you will need to obtain permission directly from the copyright holder. To view a copy of this licence, visit http://creativecommons.org/licenses/by/4.0/.

\section{References}

1. GBD 2019 Viewpoint Collaborators (2020) Five insights from the Global Burden of Disease Study 2019. Lancet 396:1135-1159. https://doi.org/10.1016/S0140-6736(20)31404-5

2. GBD 2019 Diseases and Injuries Collaborators (2020) Global burden of 369 diseases and injuries in 204 countries and territories, 1990-2019: a systematic analysis for the Global Burden of Disease Study 2019. Lancet 396:1204-1222. https://doi.org/10. 1016/S0140-6736(20)30925-9

3. Beard JR, Officer A, de Carvalho IA, Sadana R, Pot AM, Michel JP, Lloyd-Sherlock P, Epping-Jordan JE, Peeters G, Mahanani WR, Thiyagarajan JA, Chatterji S (2016) The World report on ageing and health: a policy framework for healthy ageing. Lancet 387:2145-2154. https://doi.org/10.1016/S0140-6736(15)00516-4

4. Cieza A, Causey K, Kamenov K, Hanson SW, Chatterji S, Vos T (2021) Global estimates of the need for rehabilitation based on the Global Burden of Disease study 2019: a systematic analysis for the Global Burden of Disease Study 2019. Lancet 396:2006-2017. https://doi.org/10.1016/S0140-6736(20)32340-0

5. World Health Organization, Rehabilitation 2030: A Call for Action. https://www.who.int/rehabilitation/rehab-2030-call-foraction/en/

6. Buchbinder R, van Tulder M, Oberg B, Costa LM, Woolf A, Schoene M, Croft P, Lancet Low Back Pain Series Working G (2018) Low back pain: a call for action. Lancet 391:2384-2388. https:// doi.org/10.1016/S0140-6736(18)30488-4

7. Croft P, Louw Q, Briggs AM (2020) Transforming back pain care-why, what, and how? Pain 161:2657-2658. https://doi.org/ 10.1097/j.pain.0000000000001990

8. Reynolds JP, Stautz K, Pilling M, van der Linden S, Marteau TM (2020) Communicating the effectiveness and ineffectiveness of government policies and their impact on public support: a systematic review with meta-analysis. R Soc Open Sci 7:190522. https:// doi.org/10.1098/rsos.190522

9. Briggs AM, Persaud JG, Deverell ML, Bunzli S, Tampin B, Sumi Y, Amundsen O, Houlding EM, Cardone A, Hugosdottir T, Rogers S, Pozsgai M, Slater H (2019) Integrated prevention and management of non-communicable diseases, including musculoskeletal health: a systematic policy analysis among OECD countries. BMJ Glob Health 4:e001806. https://doi.org/10.1136/ bmjgh-2019-001806

10. Hartvigsen J, Hancock MJ, Kongsted A, Louw Q, Ferreira ML, Genevay S, Hoy D, Karppinen J, Pransky G, Sieper J, Smeets RJ, Underwood M, Lancet Low Back Pain Series Working G (2018) What low back pain is and why we need to pay attention. Lancet 391:2356-2367. https://doi.org/10.1016/S0140-6736(18)30480-X 
11. Disease GBD, Injury I, Prevalence C (2018) Global, regional, and national incidence, prevalence, and years lived with disability for 354 diseases and injuries for 195 countries and territories, 1990-2017: a systematic analysis for the Global Burden of Disease Study 2017. Lancet 392:1789-1858. https://doi.org/10.1016/ S0140-6736(18)32279-7

12. World Health Organizationm: WHO guidelines on physical activity and sedentary behaviour. https://www.who.int/publications/i/ item/9789240015128

13. DALYs GBD, Collaborators H (2018) Global, regional, and national disability-adjusted life-years (DALYs) for 359 diseases and injuries and healthy life expectancy (HALE) for 195 countries and territories, 1990-2017: a systematic analysis for the Global Burden of Disease Study 2017. Lancet 392:1859-1922. https:// doi.org/10.1016/S0140-6736(18)32335-3

14. Goudet SM, Bogin BA, Madise NJ, Griffiths PL (2019) Nutritional interventions for preventing stunting in children (birth to 59 months) living in urban slums in low- and middle-income countries (LMIC). Cochrane Database Syst Rev 6:CD011695. https:// doi.org/10.1002/14651858.CD011695.pub2

15. Specker B, Thiex NW, Sudhagoni RG (2015) Does exercise influence pediatric bone? A systematic review. Clin Orthop Relat Res 473:3658-3672. https://doi.org/10.1007/s11999-015-4467-7

16. O'Connor EA, Evans CV, Burda BU, Walsh ES, Eder M, Lozano $P$ (2017) Screening for obesity and intervention for weight management in children and adolescents: evidence report and systematic review for the US preventive services task force. JAMA 317:2427-2444. https://doi.org/10.1001/jama.2017.0332

17. World Health Organization, Ageing and Health. https://www.who. int/news-room/fact-sheets/detail/ageing-and-health

18. Dreinhofer KE, Mitchell PJ, Begue T, Cooper C, Costa ML, Falaschi P, Hertz K, Marsh D, Maggi S, Nana A, Palm H, Speerin R, Magaziner J, on behalf of: the Fragility Fracture N, European Geriatric Medicine S, European Federation of National Associations of O, Traumatology, International Collaboration of Orthopaedic N, International Geriatric Fracture S, International Osteoporosis F (2018) A global call to action to improve the care of people with fragility fractures. Injury 49:1393-1397. doi: https:// doi.org/10.1016/j.injury.2018.06.032

19. Gibbs JC, MacIntyre NJ, Ponzano M, Templeton JA, Thabane L, Papaioannou A, Giangregorio LM (2019) Exercise for improving outcomes after osteoporotic vertebral fracture. Cochrane Database Syst Rev 7:CD008618. https://doi.org/10.1002/14651858.CD008 618.pub3

20. Alshahri SS, Cripps RA, Lee BB, Al-Jadid MS (2012) Traumatic spinal cord injury in Saudi Arabia: an epidemiological estimate from Riyadh. Spinal Cord 50:882-884. https://doi.org/10.1038/ sc. 2012.65

21. Lee BB, Cripps RA, Fitzharris M, Wing PC (2014) The global map for traumatic spinal cord injury epidemiology: update 2011, global incidence rate. Spinal Cord 52:110-116. https://doi.org/10. $1038 /$ sc. 2012.158
22. NEJM Catalyst, Innovations in care delivery. https://catalyst.nejm. org/doi/full/101056/CAT170558

23. Hwang J, Louie PK, Phillips FM, An HS, Samartzis D (2019) Low back pain in children: a rising concern. Eur Spine J 28:211-213. https://doi.org/10.1007/s00586-018-5844-1

24. Chu PY, Maslow GR, von Isenburg M, Chung RJ (2015) Systematic review of the impact of transition interventions for adolescents with chronic illness on transfer from pediatric to adult healthcare. J Pediatr Nurs 30:e19-27. https://doi.org/10.1016/j. pedn.2015.05.022

25. Marques A, Demetriou Y, Tesler R, Gouveia ER, Peralta M, Matos MG (2019) Healthy lifestyle in children and adolescents and its association with subjective health complaints: findings from 37 countries and regions from the HBSC study. Int J Environ Res Public Health 16:3292. https://doi.org/10.3390/ijerph16183292

26. World Health Organization, Spinal cord injury. https://www.who. int/disabilities/policies/spinal_cord_injury/en/

27. Lidal IB, Huynh TK, Biering-Sorensen F (2007) Return to work following spinal cord injury: a review. Disabil Rehabil 29:13411375. https://doi.org/10.1080/09638280701320839

28. Injury GBDTB, Spinal Cord Injury C (2019) Global, regional, and national burden of traumatic brain injury and spinal cord injury, 1990-2016: a systematic analysis for the Global Burden of Disease Study 2016. Lancet Neurol 18:56-87. https://doi.org/ 10.1016/S1474-4422(18)30415-0

29. Traeger AC, Hubscher M, Henschke N, Moseley GL, Lee H, McAuley JH (2015) Effect of primary care-based education on reassurance in patients with acute low back pain: systematic review and meta-analysis. JAMA Int Med 175:733-743. https:// doi.org/10.1001/jamainternmed.2015.0217

30. Foster NE, Anema JR, Cherkin D, Chou R, Cohen SP, Gross DP, Ferreira PH, Fritz JM, Koes BW, Peul W, Turner JA, Maher CG, Lancet Low Back Pain Series Working G (2018) Prevention and treatment of low back pain: evidence, challenges, and promising directions. Lancet 391:2368-2383. https://doi.org/10.1016/S01406736(18)30489-6

31. Reed S, Shell R, Kassis K, Tartaglia K, Wallihan R, Smith K, Hurtubise L, Martin B, Ledford C, Bradbury S, Bernstein HH, Mahan JD (2014) Applying adult learning practices in medical education. Curr Probl Pediatr Adolesc Health Care 44:170-181. https://doi.org/10.1016/j.cppeds.2014.01.008

32. World Health Organization, Patient safety. https://www.who.int/ patientsafety/en/

33. Larsson S, Lawyer P, Garellick G, Lindahl B, Lundstrom M (2012) Use of 13 disease registries in 5 countries demonstrates the potential to use outcome data to improve health care's value. Health Aff (Millwood) 31:220-227. https://doi.org/10.1377/hltha ff. 2011.0762

Publisher's Note Springer Nature remains neutral with regard to jurisdictional claims in published maps and institutional affiliations. 


\section{Authors and Affiliations}

Sami I. AlEissa ${ }^{1} \cdot$ Koji Tamai $^{2}$ (1) . Faisal Konbaz ${ }^{1} \cdot$ Ahmed Alturkistany $^{3} \cdot$ Thomas R. Blattert $^{4} \cdot$ Harvinder S. Chhabra $^{5}$. Giuseppe Costanzo ${ }^{6} \cdot$ Edward J. Dohring $^{7} \cdot$ Frank Kandziora $^{8} \cdot$ Ralph Kothe $^{9} \cdot$ Bernardo Misaggi $^{10}$. Eric J. Muehlbauer ${ }^{11}$. Paulo Pereira ${ }^{12}$. Shanmuganathan Rajasekaran ${ }^{13}$. William J. Sullivan ${ }^{14}$. Eeric Truumees $^{15}$. Yahya Alqahtani ${ }^{16}$. Hana I. Alsobayel ${ }^{17}$. Joerg Franke ${ }^{18}$. Marco G. A. Teli ${ }^{19}$. Jeffrey C. Wang ${ }^{20}$. Hazzaa M. Al-Hazzaa ${ }^{21}$. Majed Nasser Alosaimi ${ }^{22}$. Sigurd Berven ${ }^{23} \cdot$ Marco Brayda-Bruno $^{24}$. Andrew M. Briggs ${ }^{25}$. Jamiu O. Busari ${ }^{26} \cdot$ Antonello-Valerio Caserta $^{27} \cdot$ Pierre Côté $^{28} \cdot$ Marco Crostelli $^{29} \cdot$ Michael G. Fehlings $^{30}$. Robert Gunzburg ${ }^{31}$ - Sami Haddadin ${ }^{32}$. Joseph $\mathrm{Ihm}^{33}$. Alan S. Hilibrand ${ }^{34}$. Andrea Luca ${ }^{35}$ - Mazza Osvaldo ${ }^{29}$. Tim Pigott ${ }^{36}$. Dominique A. Rothenfluh ${ }^{37}$. Carlo Ruosi ${ }^{38} \cdot$ Louis-Rachid Salmi ${ }^{39} \cdot$ Ajoy P. Shetty ${ }^{13} \cdot$ Kern Singh $^{40}$. Alexander R. Vaccaro ${ }^{41}$. David A. Wong ${ }^{11} \cdot$ Mehmet Zileli $^{42} \cdot$ Margareta Nordin $^{43}$

1 National Guard Health Affairs, Riyadh, Saudi Arabia

2 Department of Orthopedics, Osaka City University, Osaka, Japan

3 King Faisal Specialist Hospital \& Research Center, Jeddah, Saudi Arabia

4 Schwarzach Orthopaedic Clinic, Schwarzach, Germany

5 Indian Spinal Injuries Center, New Delhi, India

6 Sapienza Rome University, Rome, Italy

7 Spine Institute of Arizona, Scottsdale, AZ, USA

8 Center for Spinal Surgery and Neurotraumatology, Frankfurt, Germany

9 Clinic for Spinal Surgery, Hamburg, Germany

10 Orthopaedic Institute Gaetano Pini-CTO, Milan, Italy

11 North American Spine Society, Burr Ridge, IL, USA

12 University of Porto, Porto, Portugal

13 Ganga Hospital, Coimbatore, India

14 Vanderbilt University Medical Center, Nashville, TN, USA

15 University of Texas, Austin, TX, USA

16 Presidency of State Security, Riyadh, Saudi Arabia

17 King Saud University, Riyadh, Saudi Arabia

18 Klinikum Magdeburg gGmbH, Magdeburg, Germany

19 Walton Centre NHS Trust, Liverpool, UK

20 University of Southern California Spine Center, Los Angeles, CA, USA

21 Princess Nourah Bint Abdulrahman University, Riyadh, Saudi Arabia

22 King Saud Bin Abdulaziz University for Health Sciences, Jeddah, Saudi Arabia

23 University of California San Francisco, San Francisco, CA, USA
24 IRCCS Orthopedic Institute Galeazzi, Milano, Italy

25 Curtin University, Bentley, WA, Australia

26 Maastricht University, Maastricht, Netherlands

27 ASST Gaetano Pini-CTO, Milan, Italy

28 Ontario Tech University, Oshawa, ON, Canada

29 Ospedale Bambino Gesù, Roma, Italia

30 University of Toronto and University Health Network, Toronto, ON, Canada

31 Cavell Spine Center, Brussels, Belgium

32 Munich School of Robotics and Machine Intelligence, TUM, Munich, Germany

33 Shirley Ryan AbilityLab, Northwestern Feinberg School of Medicine, Chicago, IL, USA

34 Thomas Jefferson University, Philadelphia, PA, USA

35 IRCCS Galeazzi, Milan, Italy

36 EUROSPINE, Zürich, Switzerland

37 Oxford University Hospitals NHS Foundation Trust, Oxford, UK

38 Federico II University, Naples, Italy

39 Université de Bordeaux, INSERM and Centre hospitalier universitaire de Bordeaux, Bordeaux, France

40 Midwest Orthopaedics at Rush, Rush University Medical Center, Chicago, IL, USA

41 Sidney Kimmel Medical Center, Thomas Jefferson University, Philadelphia, PA, USA

42 Ege University, Izmir, Turkey

43 Departments of Orthopaedic Surgery and Environmental Medicine, NYU Grossman School of Medicine, New York University, New York, NY, USA 